\title{
Proceeding
}

Supplementary Issue: Spring Conferences of Sports Science. International Conference on Psychology of Education Sciences \& Lifestyle.

\section{Study the correlation between alleles of MCT1 gene and enduring performance in handball players}

\author{
HIKMAT ADIL AZIZ AL-LAMI ${ }^{1}$, SARAB HUSSEIN KHALEEL ${ }^{2}$, SAHAR DAKHIL YONIS² \\ ${ }^{1}$ Department of Medical Physiology, College of Medicine, University of Al-Qadisiyah, Iraq \\ ${ }^{2}$ Department of Anatomy, College of Medicine, University of Al-Qadisiyah, Iraq
}

\begin{abstract}
The current study aimed to determine MCT1 gene A1470T polymorphism is associated it with enduring performance among elite handball players young. The community of study was chosen 100 young players of Iraqi clubs in handball game which their length $(171.83 \pm 3.060 \mathrm{~cm})$, weight $(68.33 \pm 2.160 \mathrm{~kg})$ and age $(24.4$ \pm 3.782 years). Genotyping of A1470T polymorphism of the MCT1 gene was done by the PCR-RFLP technique lactate measurement of 100 handball players was examined after testing the endurance of defensive and attack performance. Frequencies of genotypes in 100 players were AA genotype (60\%), AT genotype (30\%) and TT genotype (10\%). The mean of endurance capacity was significantly higher in AA genotype (1.01 $\pm 0.04 \mathrm{~min}$ ) versus AT genotype (1.10 $\pm 0.01 \mathrm{~min})$. (AA + AT) genotypes versus TT genotype (1.14 $\pm 0.01 \mathrm{~min})$. Mean of blood lactate concentration was significantly higher in AA genotype (16.23 \pm 0.35 $\mathrm{mMol})$ versus $(\mathrm{AT}+\mathrm{TT})$ genotypes $(13.48 \pm 0.18 ; 11.66 \pm 0.13 \mathrm{mMol})$ respectively. We concluded that the MCT1 gene A1470T polymorphism enhances enduring performance in elite handball players.

Keywords: Alleles of MCT1 gene; Enduring performance; Handball players.

\section{Cite this article as:}

Al-Lami, H.A.A., Khaleel, S.H., \& Yonis, S.D. (2020). Study the correlation between alleles of MCT1 gene and enduring performance in handball players. Journal of Human Sport and Exercise, 15(3proc), S958-S965. doi:https://doi.org/10.14198/ihse.2020.15.Proc3.47
\end{abstract}

\footnotetext{
Corresponding author. Department of Medical physiology, College of Medicine, University of Al-Qadisiyah, Iraq.

E-mail: alireza.e.amiri@gmail.com

Supplementary Issue: Spring Conferences of Sports Science. International Conference on Psychology of Education Sciences and Lifestyle.

JOURNAL OF HUMAN SPORT \& EXERCISE ISSN 1988-5202

(c) Faculty of Education. University of Alicante

doi:10.14198/jhse.2020.15.Proc3.47
} 


\section{INTRODUCTION}

The sports performance and physical fitness are a highly complex phenotype which has hygienic trait (Kambouris et all, 2012). The lactic acid system is an important element to provide energy for the tool that performs at full speed and that takes a time ranging between 30s-3min. In handball, all moves are made by the player quickly, in addition to that some physical characteristics including this system such as enduring performance and is the Efficiency of the player to perform the performance requirements for handball during competition without a decrease in the productivity and effectiveness of his performance (Allami , 2012). Some genes are responsible for athletic performance such as muscle performance, endurance capacity and body mass (Cupeiro et all, 2010). The coordinated movement for muscular tissue which needed turn gene expression. So recent research studies all types of changes that occur during physical exercise at the cellular and molecular levels (Calò \& Vona, 2008).

Monocarboxylate transport 1 gene (MCT1) is one of the genes that correlate with athletic endurance and physical fitness (Fedotovskaya et all., 2014). The role of this protein that mediates the transport of pyruvate and lactate via the plasma membrane within many tissues. MCT1 protein is found predominantly in oxidative fibres which have a high number of mitochondria (Halestrap \& Wilson, 2012). MCT1 is transported lactate to heart and red skeletal muscle for oxidized as a major fuel (Dubouchaud et all.,2000). Removal lactic acid when muscle fatigue influence by a variant of the MCT1 gene for lactate transport and intensity of performance (Bentley et all., 2009).

MCT1 is a gene located in chromosome number $1 \mathrm{p} 13.2$ and spans about $44 \mathrm{~kb}$, it is encoded to MCT1 protein which composed of 500 amino acid residues (Garcia et al.,1994).

MCT1 protein is a correlation with muscle activity when muscle inactivity reduces MCT1 expression (Wilson et al.,1998). And regulation of MCT1protein depending on calcium-dependent phosphatase and AMPactivated protein kinase (Halestrap,2009). In addition to genes, the enduring performance is determining by different factors such as intensity and type of training depending on anthropometric and morphometric characteristics of the athlete (Merezhinskaya et al.,2000).

One of the missense mutations in the MCT1 gene is genotype A1470T causing codon 490 aspartic acid instead glutamic acid. The person with T allele has a range of lactate transport $(60-70) \%$ less than normal allele (Maldonado et al.,2002).

Recent research shows a correlation between this SNP and the accumulation of lactate through training Russian athletes for rower and cohort have high frequency with AA genotype (Fedotovskaya, 2014). In our study, we aimed to determine if the MCT1 A 1470T polymorphism that affects physical performance in handball players and accumulation lactate rate in training program.

\section{METHODS}

\section{Subject}

The researchers identified the research community, they are players of Iraqi clubs participating in the Iraqi elite league. 100 players range in length $(171.83 \pm 3.060 \mathrm{~cm})$, weight $(68.33 \pm 2.160 \mathrm{~kg})$ and age $(24.4 \pm$ 3.782 years). The type of the study was descriptive to determine the endurance of defensive and attack performance and lactate measurement. 


\section{Design}

Our study classified handball players into three groups depending on their MCT1 genotype. To exam the effect MCT1 polymorphism on enduring performance and lactate accumulation in handball players by exam lactate content in the blood.

\section{Genotype}

The genotype of the players was determined by Intravenous Blood Drawing. The DNA extraction was done by the gDNA mini kit (Geneaid, USA). Then genotyping of samples for the A1470T polymorphism was done by the PCR-RFLP technique. Using forward primer 5'-AGCAAACGAGCAGAAAAAGG-3', reveres primer 5'CTGGGTCATGAACTGCTCAA-3'. (Bioneer company, Korea). The primers produce 187 bp which digest by $\mathrm{Bccl}$ restriction enzyme for $(8)$ hours at $37^{\circ} \mathrm{C}$. Then the product was running in $(6 \%)$ polyacrylamide gel electrophoresis. And stain with ethidium bromide to visualized in UV.

The amended endurance test of defensive and attack performance of handball:

The purpose of the test: Measure the player's ability to the endurance of defensive and attack performance of handball. Used equipment's: Handballs, Handball field, Plastic cones, Stopwatch.

Method of performance: The leading player stands on the $6 \mathrm{~m}$ line, and upon giving the starting signal he makes defensive moves between the plastic cones between the $6 \mathrm{~m}$ line and the $9 \mathrm{~m}$ line three times and then he takes a ball placed on the $9 \mathrm{~m}$ line and goes to perform A lightning attack by a ball to the $9 \mathrm{~m}$ line in the other half of the field to aim at the target, then he performs the same previous performance with a defensive move between the $6 \mathrm{~m}$ line and the $9 \mathrm{~m}$ line, then he takes a handball placed on the $9 \mathrm{~m}$ line to perform a lightning attack by the ball to the $9 \mathrm{~m}$ line in the other half of the field To aim at the target, and repeat the performance for three consecutive sessions without stopping.

Test conditions: Commitment to defensive moves, and what came in the manner of performance.

Recording: the performance time is calculated from the moment when the start signal is made to the moment the ball is left to the player during the third-round correction.

Endurance of defensive and attack performance test of handball for stud sample was done on Saturday,16/2/ 2019 at nine o'clock in the morning in the sports hall in Al-Qadisiyah Governorate, after which lactic acid was measured in the blood, and that Using the Lactic meter shown below, as there are three types of strips. The first is used to confirm the reading of the device, as there is a proportion of the lactic acid shown in the instructions with the device. When reading, the result must be by the instructions, otherwise, the results cannot be approved. The second strip is called a strip calibration in which there is a number on the copper slide (F5) when reading it must appear (F5) on the screen as it is used for calibration of the device and after the completion of reading the strip. The third slide is used to measure lactic acid in the blood, as it is Put sterile alcohol on a thumb of Athlete then special acupuncture needle and placed on the Strip test is directly reading after 60 seconds of the device as shown in Figures $(1,2)$. 


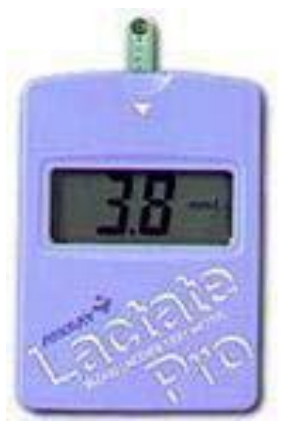

Figure 1. Illustrates the lactic meter.
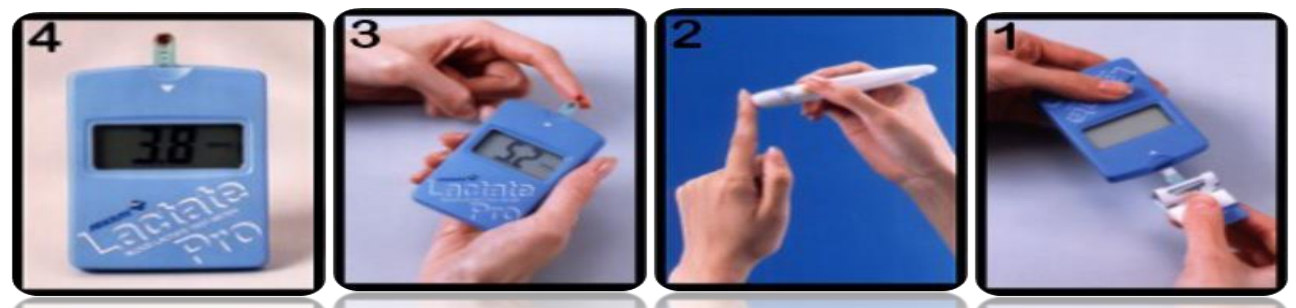

Figure 2. Illustrate steps to measurement lactic acid.

\section{Statistical analysis}

The Mean \pm SD was used to display and analyse the data involving significant results by one-way ANOVA. Statistical analyses were performed using statistical analysis software (SPSS) version 17.

\section{RESULTS}

Table 1. MCT1 genotype distribution in handball players.

\begin{tabular}{ll}
\hline Genotyping & No.(100\%) \\
\hline AA & $60(60 \%)$ \\
AT & $30(30 \%)$ \\
TT & $10(10 \%)$ \\
Total & 100 \\
\hline
\end{tabular}

Table 1 shows the distributions of MCT1 genotypes in handball players AA 60\%; AT 30\%; TT 10\% was in Hardy-Weinberg equilibrium with no errors for genotyping.

Table 2. The Endurance of defensive and attack performance among the genotyping of MCT1 A1470T polymorphism in handball players.

\begin{tabular}{lcccccc} 
Genotype & N & Mean (Minute) & SD & p1 & p2 & p3 \\
\hline AA & 60 & 1.01 & 0.04 & $<.001$ & $<.001$ & $<.001$ \\
AT & 30 & 1.10 & 0.01 & & & \\
TT & 10 & 1.14 & 0.01 & & & \\
\hline
\end{tabular}


Table 2 shows regarding, the endurance of defensive and attack performance of handball players, significant differences were found in the AA group (1.01 \pm 0.04$)$ versus AT group $(1.10 \pm 0.01)$ and AA group with AT group versus TT group(1.14 \pm 0.01$)(p<.001)$. In detail, handball players with AA and AT genotype had high endurance capacity compare with the TT group. This means, there was a correlation between MCT1 SNP and the endurance of defensive and attack performance of handball players.

Table 3. Blood lactate among the genotyping of MCT1 A1470T polymorphism in handball players.

\begin{tabular}{lcccccc}
\hline Genotype & N & Mean (mMol) & SD & p1 & p2 & p3 \\
\hline AA & 60 & 16.23 & 0.35 & $<.001$ & $<.001$ & $<.001$ \\
AT & 30 & 13.48 & 0.18 & & & \\
TT & 10 & 11.66 & 0.13 & & & \\
\hline
\end{tabular}

Note: P1: AA versus AT; P2: AA versus TT; P3: AT versus TT.

Table 3 shows the measurement of blood lactate in three genotypes showed significant differences in high lactate concentration in the AA group (16.23 \pm 0.35$)$; AT group (13.48 \pm 0.18$)$ versus TT group (11.66 \pm $0.13)(p<.001)$.

\section{DISCUSSION}

The handball sport is a game in which the anaerobic system prevails. Handball players must have a special endurance because moving them from defence to attack and vice versa. This leads to an accumulation of lactic acid in high concentration in muscles and blood of players, otherwise, the players stop playing and get early fatigue (Abo Al-Ouala, 2003; Vetter, 2007). Changes in MCT1content are more common in response to contractile activity, whereas changes in lactate transport capacity typically occur in response to changes in metabolic pathways (Thomas et al., 2012).

Training experts believe that endurance is one of the key factors because it means the ability of the individual to maintain his level at a constant rate almost through the competition period" (2). Hence the importance of research to know the relationship between types of alleles in handball players and the ability to endurance the impact of anaerobic exercise.

MCT1 protein found in plasma membrane skeletal muscle. It has a role in exercise tolerance with ancillary protein CD147 (Mykkänen et al., 2011). Acute exercise regulates MCT1 expression and affected by many factors including nutrition, hypoxia and lactate production (Al-Haggar et al., 2017). This protein transports the proton and lactate through the plasma membrane of oxidation in muscle fibres. MCT1 protein is required for the production of lactate with white muscle fibres to enter lactate into red muscles for use lactate as the main storage of respiratory energy (Kobayashi, 2005). Therefore, the description of this missense mutation A1470T in the MCT1 gene has a role in genetic variation. Although this mutation did not change the function of MCT1 protein, there a significant effect on the polymorphism of the gene. A recent study found that polymorphism of this gene with performance endurance showed significant differences between the genetic groups.

Our results showed that the MCT1 A 1470T polymorphism of 100 handball players carrying allele A and AA genotype we high in the performance tolerance ratio with high lactate concentration in the blood compared to TT genotype. This result agrees with Al-Haggar et al suggested that A allele and AA genotype is the best, therefore the exercise and epigenetic factors increase of MCT1 protein function. So, the promoter region is active in several transcriptional factors (Al-Haggar et al., 2017). During exercise, handball players depended 
on anaerobic metabolism and then followed an aerobic steady state. This indicates the use of anaerobic metabolism will increase lactate concentration during the first minutes of the exercise and then maintain muscle activity until the end of the exercise using respiratory fuel of blood flow and oxidation of muscles during the aerobic breathing phase of the exercise. As a result, fatigue comes faster, which might lead to a limitation of endurance performance (Mykkänen et al., 2011).

Pilegaard et al showed lactate capacities were different in individuals and they have a very high capacity by the extent of training and inherent athletic ability (Pilegaard et al., 1994). Our result show that AA and AT genotype groups have positive parameter for exercise performance depending on higher maximal lactate concentration in short time for Endurance of defensive and attack performance test. As that muscle work in this state does not lead to rapid appearance fatigue so may be endure this condition for a long time and some researchers consider it an anaerobic threshold (Abo-Alola \&Ahmad ,2003).

Results in recent study were in agreement with previous studies in female rowers with AA genotype had high blood lactate than AT and TT genotypes. Several studies showed higher accumulation in T allele carriers. Recent research has found higher blood lactate levels in AA genotype carriers compared to carriers of AT and TT genotypes (Cupeiro et al., 2012).

So, T allele of A1470T polymorphism in MCT1 the gene is functionally important that leads to impaired lactate transport in the muscle fibre to oxidative (Calò \& Vona, 2008). And accumulation the lactate in blood after high-intensity exercises this does not allow newly formed lactate. Therefore, player fells fast fatigue and his endurance was limited action.

Some studies mention that high a level of lactate induced to muscle hypertrophy by endogenous anabolic factors (Al-Haggar et al., 2017). Olga suggested the hypertrophy of muscles reach a high -power athletic level (Calò \& Vona,2008).

Finally, our study recognize MCT1 A allele is a genetic marker associated with a good endurance performance to selective handball players. And we suggested studying other genes to assessment handball players.

\section{CONCLUSION}

This research summaries that A1470T polymorphism of MCT1 gene is a genetic evidence correlation with enduring performance and lactate concentration in blood for athletes after training exercise.

\section{REFERENCES}

Abo-Alola,A. \&Ahmad ,N.A.(2003).Fitness physiology.cairo,Dar Al-fakar Al-Arabi,p.277.

Abo Al-Ouala,A.(2003).Training and sport physiology.cairo,Al-fakar al arabi.ed1,p.294.

Al-haggar, M.; Eid, A.; Ramadan,W.; D Abdel-hady,D.; and Hassan,R.(2017).MCT1 polymorphism among Egyptian children and adolescents as a useful predictor for physical fitness and muscle fatigue. J Syst Biol Proteome Res, Volume 1 Issue.

Allami,H.A.(2012)."The impact of Anaerobic Exercises and Phosphate creatine on Specal Endurance with Reference to Lactic Acid Concentration (CPK- L.D.H) of Al-Qadisiyah Governorate Youth Team of Handball" . Unpublished Ph.D. thesis. The college of sport education, University of AL-Qadisiyah. Iraq. 
Bentley DJ, Roels B, Thomas C, et al.(2009). The relationship between monocarboxylate transporters 1 and 4 expression in skeletal muscle and endurance performance in athletes. Eur J Appl Physiol. 2009;106:465-471. https://doi.org/10.1007/s00421-009-1034-5

Calò,C. \& Vona,G. (2008).Gene polymorphisms and elite athletic performance. Journal of Anthropological Sciences Vol. 86 , pp. 113-13.

Cupeiro R, Benito PJ, Maffulli N, Calderon FJ, Gonzalez-Lamuno D.(2010). MCT1 genetic polymorphism influence in high intensity circuit training: a pilot study. J Sci Med Sport; 13: 526-30. https://doi.org/10.1016/j.jsams.2009.07.004

Cupeiro R, Gonzalez-Lamuno D, Amigo T, (2012). Influence of the MCT1-T1470A polymorphism (rs1049434) on blood lactate accumulation during different circuit weight trainings in men and women. J Sci Med Sport.15:541-547. https://doi.org/10.1016/j.jsams.2012.03.009

Dubouchaud H, Butterfield GE, Wolfel EE, Bergman BC, Brooks GA.(2000). Endurance training, expression, and physiology of LDH, MCT1 and MCT4 in human skeletal muscle. Am J Physiol Endocrinol Metab;278. https://doi.org/10.1152/ajpendo.2000.278.4.E571

Fedotovskaya,O.; Mustafina,L.; Popov,D.;Vinogradova,O.; and Ahmetov,I.(2014). A Common Polymorphism of the MCT1 Gene and Athletic Performance. International Journal of Sports Physiology and Performance, 9, 173 -180. https://doi.org/10.1123/ijspp.2013-0026

Garcia CK, Li X, Luna J, .(1994). cDNA cloning of the human monocarboxylate transporter 1 and chromosomal localization of the SLC16A1 locus to 1p13. 2-p12.Genomics. 15; 23(2):500-3. https://doi.org/10.1006/geno.1994.1532

Halestrap AP.(2009). Monocarboxylate Transporter 1. UCSDNature Signaling Gateway Molecule Page. https://doi.org/10.1038/mp.a001490.01

Halestrap AP, Wilson MC.(2012). The monocarboxylate transporter family-role and regulation. IUBMB Life;64(2):109-119. https://doi.org/10.1002/iub.572

Kambouris M, Ntalouka F, Ziogas G, Maffulli N.(2012). Predictive Genomics DNA Profiling for Athletic Performance. Recent Pat DNA Gene ; 6:229-39. https://doi.org/10.2174/187221512802717321

Kobayashi M, Fujita I, Itagaki S, Hirano T, Iseki K.(2005). Transport mechanism for L-lactic acid in human myocytes using human prototypic embryonal rhabdomyosarcoma cell line (RD) cells. Biol Pharm Bull. ; 28 (7):1197-1201. https://doi.org/10.1248/bpb.28.1197

Maldonado S., Mujika L. \& Padilla S. (2002). Influence of body mass and weight on the energy cost of running in highly trained middle- and long distance runners. Int. J. Sports Med., 23:268-272. https://doi.org/10.1055/s-2002-29083

Merezhinskaya N, Fishbein WN, Davis $\mathrm{Jl}$, et al.(2000). Mutations in MCT1 cDNA in patients with symptomatic deficiency in lactate transport. Muscle Nerve. 1; 23(1):90-7. https://doi.org/10.1002/(SICI)1097-4598(200001)23:1<90::AID-MUS12>3.0.C0;2-M

Mykkänen AK, Koho NM, Reeben M, et al.(2011).MCT1, MCT4 and CD147 gene polymorphisms in healthy horses and horses with myopathy. Res Vet Sci. 31; 91(3):473-7. https://doi.org/10.1016/j.rvsc.2010.09.025

Pilegaard H, Bangsbo J, Richter EA, et al.(1994). Lactate transport studied in sarcolemmal giant vesicles from human muscle biopsies: relation to training status. J Appl physiol. 1; 77(4):1858-62. https://doi.org/10.1152/jappl.1994.77.4.1858

Thomas C, Bishop DJ, Lambert K, et al.(2012). Effects of acute and chronic exercise on sarcolemmal MCT1 and MCT4 contents in human skeletal muscles: Current status. Am J Physiol Regul Integr Comp Physiol. 1; 302(1):R1-4. https://doi.org/10.1152/ajpregu.00250.2011

Vetter,RE.(2007). Effects of six wam-up protocols on sprint and jump performance.J .strength cond Res 21:819-823. https://doi.org/10.1519/00124278-200708000-00028 
Wilson MC, Jackson VN, Heddle C, et al.(1998). Lactic acid efflux from white skeletal muscle is catalyzed by the monocarboxylate transporter isoform MCT3. J Biol Chem. 26; 273(26):15920-6. https://doi.org/10.1074/jbc.273.26.15920

\section{(c)}

This work is licensed under a Attribution-NonCommercial-NoDerivatives 4.0 International (CC BY-NC-ND 4.0). 